OPEN ACCESS

Edited by:

Prasad V. Katakam,

Tulane University, United States

Reviewed by:

Shanting Zhao,

Northwest A\&F University, China

Diego Sepulveda-Falla,

University Medical Center

Hamburg-Eppendorf, Germany

*Correspondence:

Gerd Kempermann

gerd.kempermann@dzne.de;

gerd.kempermann@tu-dresden.de

Received: 15 October 2020 Accepted: 08 April 2021

Published: 21 May 2021

Citation:

Ehret $F$, Moreno Traspas $R$, Neumuth M-T, Hamann B, Lasse D

and Kempermann $G$ (2021) Notch3-Dependent Effects on Adult Neurogenesis

and Hippocampus-Dependent Learning in a Modified Transgenic Model of CADASIL.

Front. Aging Neurosci. 13:617733. doi: 10.3389/fnagi.2021.617733

\section{Notch3-Dependent Effects on Adult Neurogenesis and Hippocampus-Dependent Learning in a Modified Transgenic Model of CADASIL}

\author{
Fanny Ehret ${ }^{1}$, Ricardo Moreno Traspas ${ }^{2}$, Marie-Theres Neumuth ${ }^{1}$, Bianca Hamann ${ }^{1}$, \\ Daniela Lasse ${ }^{1}$ and Gerd Kempermann ${ }^{1,2 *}$
}

${ }^{1}$ German Center for Neurodegenerative Diseases (DZNE), Dresden, Germany, ${ }^{2}$ Center for Regenerative Therapies Dresden, TU Dresden, Dresden, Germany

We and others have reported that Notch3 is a regulator of adult hippocampal neurogenesis. Cerebral Autosomal Dominant Arteriopathy with Subcortical Infarcts and Leukoencephalopathy (CADASIL), the most common genetic form of vascular dementia, is caused by mutations in Notch3. The present study intended to investigate whether there is a correlation between altered adult hippocampal neurogenesis and spatial memory performance in CADASIL transgenic mice. To overcome visual disabilities that hampered behavioral testing of the original mice (on an FVB background) we back-crossed the existing TgN3 ${ }^{R 169 C}$ CADASIL mouse model onto the C57BL/6J background. These animals showed an age-dependent increase in the pathognomonic granular osmiophilic material (GOM) deposition in the hippocampus. Analysis in the Morris water maze task at an age of 6 and 12 months revealed deficits in re-learning and perseverance in the CADASIL transgenic mice. Overexpression of Notch3 alone resulted in deficits in the use of spatial strategies and diminished adult neurogenesis in both age groups. The additional CADASIL mutation compensated the effect on strategy usage but not on adult neurogenesis. In brain bank tissue samples from deceased CADASIL patients we found signs of new neurons, as assessed by calretinin immunohistochemistry, but no conclusive quantification was possible. In summary, while our study confirmed the role of Notch3 in adult neurogenesis, we found a specific effect of the CADASIL mutation only on the reversion of the Notch3 effect on behavior, particularly visible at 6 months of age, consistent with a loss of function. The mutation did not revert the Notch3-dependent changes in adult neurogenesis or otherwise affected adult neurogenesis in this model.

Keywords: adult neurogenesis, CADASIL, dentate gyrus, hippocampus, Notch3, spatial learning, human brain, mouse model

Abbreviations: BrdU, Bromodeoxyuridine; CADASIL, Cerebral autosomal dominant arteriopathy with subcortical infarcts and leukoencephalopathy; DG, dentate gyrus; GFAP, glial fibrillary acidic protein; GOM, granular osmiophilic material; PFA, paraformaldehyde; N3, Notch3; RT, room temperature; TBS, tris-buffered saline; $\mathrm{TgN} 3{ }^{\mathrm{WT}}$, transgenic mice overexpressing rat wild type Notch3; $\operatorname{TgN}^{R 169 \mathrm{C}}$, transgenic mice overexpressing rat CADASIL mutant Notch3; SGZ, subgranular zone. 


\section{INTRODUCTION}

Cerebral Autosomal Dominant Arteriopathy with Subcortical Infarcts and Leukoencephalopathy (CADASIL), the most common genetic cause of stroke and vascular dementia, results in accumulation of granular osmiophilic material (GOM) in small and medium sized arteries (Chabriat et al., 2009). We previously identified GOMs in the vasculature of the adult hippocampus in an established transgenic mouse model overexpressing Notch3 (N3) with a CADASIL-causing point mutation (Ehret et al., 2015). In that model we saw effects on adult hippocampal neurogenesis but could not assess any potential role in hippocampus-dependent behavior, because the existing mice, which are on a FVB background, cannot be feasibly tested for spatial memory because of a genetic visual deficit (Voikar et al., 2001; Farley et al., 2011). The current project aimed at overcoming that limitation in order to support our original hypothesis that neurogenesis-related impairments due to the N3 mutation in neural stem cells might contribute to the overall phenotype in CADASIL.

The hippocampus is one of the first structures affected in dementias, playing an essential role in memory processing. Particularly the consolidation of declarative memory, which includes semantic and episodic memory, is processed by the hippocampus (O'Keefe and Dostrovsky, 1971; reviewed by Morris, 2007). Even though only a few studies have specified the memory deficits seen in CADASIL patients and despite the limitations of the neuropsychological assessment strategies used, some interesting commonalties have arisen. CADASIL patients often present deficits in episodic memory, executive function and working memory prior to stroke and age-dependent cognitive decline (Buffon et al., 2006; Epelbaum et al., 2011). This pattern of memory impairment suggests, besides the involvement of subcortical-frontal regions, connections to the hippocampal subfields. Furthermore, a correlation has been identified between hippocampal volume and cognitive performance in CADASIL patients, independent of vascular lesions (O'Sullivan et al., 2009). Hence, these findings point to potential role of the hippocampus in the manifestation of CADASIL.

Besides its pivotal role in memory processing, the hippocampus is also unique in that it maintains lifelong adult neurogenesis. The current view suggests that neurogenesis in this region provides increased plasticity, which is critical for lifelong cognitive flexibility (Burghardt et al., 2012; Kempermann, 2012; Spalding et al., 2013; Garthe et al., 2014). This process is tightly controlled by internal and external factors acting on residing stem and progenitor cells. The Notch super-family is one of such transcriptional regulators that play a central role in stem cell quiescence and maintenance, progenitor cell proliferation and differentiation in the developing and adult brain (Ehm et al., 2010; Imayoshi et al., 2010; Lugert et al., 2010). Since CADASIL is due to a diversity of point mutations in N3, the Notch signaling pathway is of particular relevance. Although most of the work focuses on Notch1 (N1), some aspects regarding the critical function of $\mathrm{N} 3$ in stem cell quiescence and neurogenesis have been identified (Kawai et al., 2017; Than-Trong et al., 2018). In adult mice, N3 is expressed in neural stem and progenitor cells in the subependymal zone of the lateral ventricles (Kawai et al., 2017) and the subgranular zone of the hippocampus (Ehret et al., 2015). Importantly, our previous research identified N3 as a critical regulator of precursor cell proliferation and differentiation in the neurogenic niche of the murine hippocampus (Ehret et al., 2015). Although a detailed analysis in human cells and tissues is still lacking, these findings already suggest that $\mathrm{N} 3$ might exert regulatory influences on neuronal plasticity that could impact hippocampus-dependent learning and memory.

The N3 signaling pathway is of outstanding relevance in CADASIL, since mutations in the N3 gene are disease-causative. We already proved the presence of altered hippocampal neurogenesis independent to overt vascular abnormalities in a transgenic mouse model of CADASIL (Ehret et al., 2015). In the current study we aimed at confirming whether N3 dysfunction might be an additional underlying mechanism accounting for the learning and memory deficits seen in CADASIL patients, possibly independent of vascular dysfunction but related to a dysfunction in neural stem cells in the hippocampus. For that purpose, we backcrossed the established mouse model $\mathrm{TgN} 3^{R 169 \mathrm{C}}$ (Joutel et al., 2010) onto a C57BL/6J background in order to allow unconstrained behavioral testing in the classical Morris water maze task. We used a concrete testing paradigm, which we had previously identified as highly sensitive to the contribution of adult-generated neurons to spatial learning (Garthe et al., 2009, 2014). Additionally, we intended to investigate whether we could find signs of altered adult hippocampal neurogenesis in samples from CADASIL patients.

\section{MATERIALS AND METHODS}

\section{Animals and Tissue Preparation}

$\mathrm{TgN}_{3}{ }^{\mathrm{WT}}$ and $\mathrm{TgN} 3^{R 169 C}$ generated by Joutel et al. (2010) and crossed back for 10 generations to C57BL/6J (Charles River), were maintained at the CRTD - Center for Regenerative Therapies Dresden, Dresden, Germany. WT littermates from both strains were used as controls. All experiments were conducted in accordance with the applicable European and National regulations (Tierschutzgesetz) and approved by the responsible authority (Landesdirektion Dresden, approval number 249168.11-1/2012-26). Animals were maintained on a $12 \mathrm{~h}$ light/dark cycle with food and water provided ad libitum. $\mathrm{TgN} 3^{\mathrm{WT}}$ and $\mathrm{TgN} 3^{R 169 C}$ mice were genotyped by PCR (Notch 3 forward: 5' TTC AGTGGTGGCGGGCGTC 3' Notch3 reverse: 5'GCCTACAGGTGCCACCATTA CGGC 3'; Vector forward: $5^{\prime}$ AACAGGAAGAATCGCAACGTTAAT 3' Vector reverse: 5' AATGCA GCGATCAACGCCTTCTC $3^{\prime}$ ). Notch3 PCR products from $\mathrm{TgN} 3^{\mathrm{WT}}$ and $\mathrm{TgN} 3^{R 169 C}$ mice were sequenced and the genetic mutation site was identified to confirm the correct genotype of the strains used. The effect on protein expression has been analyzed in the original $\mathrm{TgN} 3^{\mathrm{WT}}$ and $\mathrm{TgN} 3^{R 169 C}$ mice and is shown in Supplementary Figure 4.

Female and male C57BL/6J, TgN3 ${ }^{\mathrm{WT}}$, and $\mathrm{TgN}^{R 169 C}$ mice received intraperitoneal injections of 5-bromo-2-deoxyuridine (BrdU, Sigma-Aldrich) at $50 \mathrm{mg} / \mathrm{kg}$, dissolved in sterile $0.9 \%$ 
$\mathrm{NaCl}(10 \mathrm{mg} / \mathrm{ml})$. BrdU was delivered three times every $6 \mathrm{~h}$ for 6 months old animals and seven times every $24 \mathrm{~h}$ for 12 months old animals. Mice were killed 28 days after BrdU administration by using a mixture of ketamine and xylazine and transcardial perfusion with $0.9 \% \mathrm{NaCl}$ and $4 \%$ paraformaldehyde (PFA). The brains were left in $4 \%$ PFA for $24 \mathrm{~h}$ at $4^{\circ} \mathrm{C}$, transferred to $30 \%$ sucrose and cut into $40 \mu \mathrm{m}$ thick serial coronal sections on a freezing microtome (HM430, Thermo Scientific). Sections were stored at $-20^{\circ} \mathrm{C}$ in cryoprotectant solution (25\% ethylene glycol, $25 \%$ glycerol in $0.1 \mathrm{M}$ phosphate buffer, $\mathrm{pH} 7.4$ ).

\section{Human Samples}

Post-mortem human hippocampus samples $(N=7$ CADASIL and $N=6$ Control samples) were obtained from the CADASIL brain bank, Leiden University, Netherlands (age range 4870 years, including both sexes). Out of the seven CADASIL patients, six had a mutation on exon 4 and one in exon 8 . The modeled R169C mutation was not present in the human samples. All participants gave informed consent that their samples could be used for research and publication, nevertheless to prevent traceability the data are only presented in charts. For details on the influence of age, sex or post mortem delay on the obtained (but ultimately inconclusive) data see Supplementary Figure 1.

\section{Immunohistochemistry}

\section{Animal Tissue}

As described previously (Kempermann et al., 2003), for BrdU detection every sixth brain section from C57BL/6J, TgN3 ${ }^{\mathrm{WT}}$, $\mathrm{TgN} 3^{R 169 C}$ animals at 6 months and 12 months of age were used (group size at 6 months WT $=15, \operatorname{TgN} 3$ both 12 and at 12 months WT $=19, \mathrm{TgN} 3$ both 13 ). Briefly for BrdU detection, sections were quenched with $0.6 \% \mathrm{H}_{2} \mathrm{O}_{2}$ for $30 \mathrm{~min}$, incubated in $2 \mathrm{~N} \mathrm{HCl}$ for $30 \mathrm{~min}$ at $37^{\circ} \mathrm{C}$ followed by $1 \mathrm{~h}$ blocking with $\mathrm{TBS}^{++}$(10\% donkey serum, $0.2 \%$ Triton-X 100 in TBS) and incubation in monoclonal rat anti-BrdU antibody (1:500; OBT0030, Serotec) overnight at $4^{\circ} \mathrm{C}$ in $\mathrm{TBS}^{+}$(3\% donkey serum in TBS). For calretinin detection an analog protocol was used, but without the $\mathrm{HCl}$ denaturing step. Sections were incubated with primary antibody rabbit anti-calretinin (1:2000, CR7697, Swant). To determine the total number of labeled cells, the peroxidase method was used with biotinylated donkey anti-rat or anti-rabbit antibody (similarly as described for the human tissue). However, no counter stain was performed and sections were mounted on gelatine-coated slides and cover-slipped with Neo-Mount (Merck). For phenotyping of $\mathrm{BrdU}^{+}$cells, immunofluorescence was performed. Free-floating sections were washed, incubated with $2 \mathrm{~N} \mathrm{HCL}$ for $30 \mathrm{~min}$ at $37^{\circ} \mathrm{C}$, blocked for $1 \mathrm{~h}$ in $\mathrm{TBS}^{++}$and incubated over night at $4^{\circ} \mathrm{C}$ with the following primary antibodies: rat anti-BrdU (as above), mouse anti-NeuN (1:500; MAB377, Millipore), rabbit anti-S100 $\beta$ (1:1000; ab52642, Abcam). The next day, sections were washed and incubated with secondary antibody for $2 \mathrm{~h}$ at RT. All secondary antibodies were purchased from Dianova: anti-mouse Dye-Light 549, antirat Alexa 488, anti-rabbit Alexa 647. After a final washing step, sections were incubated for $10 \mathrm{~min}$ in Hoechst (1:4000 in TBS; 33342, Sigma-Aldrich) and then mounted on glass slides using 2.5\% PVA-DABCO.

\section{Human Tissue}

Paraffin-fixed sections of $5 \mu \mathrm{m}$ thickness were taken from three different blocks per human hippocampus. Per patient six sections two per each block were analyzed. Tissue sections were dewaxed with xylene and rehydrated with decreasing concentrations of ethanol. Unmasking was performed using $1 \mathrm{mM}$ EDTA $(\mathrm{pH}$ 8 ) at $110^{\circ} \mathrm{C}$ in a pressure cooker for $5 \mathrm{~min}$. Sections were afterward incubated with $3 \% \mathrm{H}_{2} \mathrm{O}_{2}$ for $30 \mathrm{~min}$, blocked for $1 \mathrm{~h}$ in TBS $^{+}$(containing 10\% donkey serum) and subsequently AvidinBiotin blocked (SP2001, Vector labs) followed by incubation with calretinin antibody (1:2000, CR7697, Swant) overnight at $4^{\circ} \mathrm{C}$ in $\mathrm{TBS}^{+}$(containing 5\% donkey serum).

To determine the number of labeled cells, the peroxidase method (Vectastain Elite ABC kit, Vector laboratories) was used with biotinylated donkey anti-rabbit antibody (1:500, Dianova) and diaminobenzidine (DAB, Sigma) as a chromogen. Sections were finally haematoxylin counter stained (RichardAllan Scientific Hematoxylin, Thermo Scientific), sequentially dehydrated and cover-slipped with Entellan (Sigma-Aldrich).

\section{Image Quantification}

Bromodeoxyuridine and calretinin cell quantification were performed on coded slides using widefield light microscopy with a Leica microscope (DM 750, Leica). The number of immunopositive $(+)$ cells present in the SGZ of the DG was quantified by manually counting all DAB-positive cells present within $40 \mu \mathrm{m}$ of the granular cell layer of the DG formation (i.e., from Bregma -1.06 to Bregma -3.88). Fluorescence images for BrdU phenotyping were obtained on a fluorescence microscope with 2D structured illumination (ApoTome.2, Zeiss). Images were processed with Zen software (Zeiss), Fiji and Illustrator CS5 (Adobe). Only general contrast and color level adjustments were made; otherwise images were not digitally manipulated. Net neurogenesis and gliogenesis were calculated for each animal separately by multiplying the proportion of BrdU differentiation obtained through fluorescent double labeling $\left(\mathrm{NeuN}^{+} \mathrm{BrdU}^{+}\right.$or $\left.\mathrm{S} 100 \beta^{+} \mathrm{BrdU}^{+}\right)$with the number of $\mathrm{BrdU}^{+}$ cells obtained through DAB.

\section{Morris Water Maze Task}

Mice were trained in the reference memory version of the Morris water maze task to locate a hidden escape platform in a circular pool ( $2 \mathrm{~m}$ diameter). In opaque water (by adding non-toxic titan white) at $19-20^{\circ} \mathrm{C}$, mice had to swim six trials a day for five consecutive days for 6 months-old mice, or seven consecutive days for 12 months-old mice. The experimental design (see Figures 2A, 4A) contained 3 or 4 days acquisition (for 6 and 12 months old mice, respectively) followed by 2 or 3 days of reversal, where the platform position was switched to the opposite quadrant. Mice were released every day from a new starting position and allowed to search for the hidden platform for a maximum of $120 \mathrm{~s}$. During each day the starting position remained constant. At the end of each trial and irrespective of trial performance, mice were guided to the platform and allowed to remain there for at least $15 \mathrm{~s}$. At the last day a final trial with a visual platform in a new position was performed to evaluate the visual abilities of the mice. Swim paths were recorded using 
EthoVision (Noldus) and further analyzed using Matlab (The Mathworks). To visualize spatial preference for the goal position in the probe trials, a heat map like occupancy plot was divided into $10 \mathrm{~cm} \times 10 \mathrm{~cm}$ wide sectors and the probability of an animal to be found in each sector was calculated. Search strategies were classified according to parameters and an algorithm described in our previous study (Garthe et al., 2014), originally based on (Balschun et al., 2003). Strategies were defined by no more than two parameters that are not dependent on pool dimensions. In detail, the swim path data from EthoVision (Noldus) were used to derive the time-tagged $\mathrm{x}, \mathrm{y}$-coordinates for the dominant search strategies by an algorithm implemented in Matlab (Mathworks). For analysis of these search strategies a logistic regression model was applied and evaluated using the working environment $\mathrm{R}$ (for details see statistics).

\section{Electron Microscopy}

Female and male mice were perfused with $0.9 \% \mathrm{NaCl}$ followed by Karnovsky's fixative (2\% glutaraldehyde, 2\% paraformaldehyde, $20 \mathrm{mM}$ HEPES). The brains were left in Karnovsky solution overnight followed by vibratome sectioning (Model 1200 Leica) at a thickness of $200 \mu \mathrm{m}$. Tissue was contrasted for $2 \mathrm{~h}$ in $1 \% \mathrm{OsO}_{4}$ at $4^{\circ} \mathrm{C}$, washed, en bloc contrasted with $1 \%$ uranyl acetate for $2 \mathrm{~h}$ at $4^{\circ} \mathrm{C}$, washed and gradually dehydrated in ethanol. This was followed by infiltration of Epon 812 resin, embedding in molds and polymerization at $60^{\circ} \mathrm{C}$ for $24 \mathrm{~h}$. Semithin sections were stained with $1 \%$ toluidine blue and $0.5 \%$ Borax (TB/Borax) and inspected with widefield microscope BZ 8000 (Keyence). Ultrathin $70 \mathrm{~nm}$ sections were analyzed on a transmission electron microscope (Morgagni 268D, FEI).

\section{Statistics}

For analysis of human post-mortem samples we used unpaired $t$-test since data was normally distributed.

For analysis of adult neurogenesis rates in transgenic animals we used one-way ANOVA, since the data passed the D'Agostino \& Pearson normality test, with Bonferroni post-hoc test.

For statistical analysis of the effect of $\mathrm{WT}, \mathrm{TgN} 3 \mathrm{WT}$, and $\mathrm{TgN} 3^{R 169 C}$ on water maze performance (swim speed, latency, and path length), we performed the non-parametric testing of Friedman with Dunn's post-hoc test since the data was not normally distributed. For probe trial performance we used Kruskal-Wallis test at 6 months of age since data was not normally distributed, and one-way ANOVA at 12 months of age since data was normally distributed (tested with D'Agostino \& Pearson normality test).

For statistical analysis of the effect of $\mathrm{WT}, \mathrm{TgN} 3 \mathrm{WT}$, and $\mathrm{TgN} 3^{R 169 C}$ on the search strategies, we applied a logistic regression (LR) (as discribed previously Garthe et al., 2016). Using the LR model with nested effect, we estimated the odds ratios for the three different genotypes (WT, TgN3 3 T, and TGN $3^{R 169 C}$ ), thus comparing the chance of using more versus less hippocampus-dependent search strategies. Corresponding $p$-values are based on ANOVA. Calculations for search strategy analysis were done in working environment $\mathrm{R}$, all other statistical calculations were done in Prism 7 (GraphPad).

\section{RESULTS}

Based on the previous observation of reduced adult hippocampal neurogenesis (Ehret et al., 2015) in the CADASIL transgenic mouse model established by Joutel et al. (2010), we aimed at identifying behavioral deficits in hippocampus-dependent spatial learning by the Morris water maze task. Therefore, this CADASIL transgenic mouse model was back-crossed onto the C57BL/6J background (B6) to overcome the limitations of the FVB/N background (Pugh et al., 2004) like impaired vision (Voikar et al., 2001).

\section{Accumulation of Granular Osmiophilic Material Starts at 6 Months in CADASIL Transgenic Mice on the B6 Background}

We first confirmed that in the new backcrossed model, neuropathological characteristics of CADASIL would be maintained. Accumulations of electron dense GOMs in small and medium sized arteries, a key feature of the disease process, appears in some transgenic animal models but not in all. Especially in the used animal model of $\mathrm{TgN} 3^{R 169 C}$ on $\mathrm{FVB} / \mathrm{N}$ background, GOM deposits started to occur at 5 months in the pial arteries and became widely distributed throughout the brain by 10-12 months of age (Joutel et al., 2010). On the B6 background, we now carried out a detailed electron microscopic analysis to observe the disease progression. Surprisingly, we found GOM accumulations already at 6 months of age in $\operatorname{TgN} 3^{R 169 C}$ on C57BL/6 background in the hippocampus (Figure 1). GOMs can be found close to the 3rd ventricle and around medium-sized vessels of the hippocampal fissure.

\section{Deficits in Hippocampus-Dependent Learning in Aged TgN3 ${ }^{\mathrm{WT}}$ and $\mathrm{TgN}^{R 169 C}$ Mice on the B6 Background}

An extended protocol was used for this task, consisting of 4 days of acquisition and 3 days of reversal, to cope with age-dependent deficits (experimental protocol Figure 2A). At 12 months of age, the transgenic mice showed specific deficits in relearning of a new platform position in the old context (reversal) while the initial acquisition was not impaired. In detail, the analysis of latency to find the hidden platform was unimpaired (Chi-Square $=0.857$, $p=0.768$; Figure 2C), but since swim speed differed significantly (Chi-Square $=12.29, p=0.003$ with $\mathrm{TgN} 3^{\mathrm{WT}}<\mathrm{TgN} 3^{R 169 C}$, $p=0.0015$; Figure 2D), the analysis of path lengths is a more reliable measure (Chi-Square $=6, p=0.05$ with $\mathrm{TgN} 3{ }^{\mathrm{WT}}$ vs. $\operatorname{TgN}^{R 169 C} p=0.048$; Figure 2B). Relearning of a new platform position was impaired in CADASIL mice, as the analysis of pathlength during reversal showed (Chi-Square $=6, p=0.027$ with WT vs. $\left.\operatorname{TgN} 3^{R 169 C} p=0.04\right)$. Nevertheless, the initial memory of the previous platform position was not impaired, as analyzed during a probe trial by measuring the time the mouse spent in the relevant target zone $\left[F_{(2,40)}=1.667, p=0.20\right]$ and the number of former goal crossings $\left[F_{(2,40)}=0.86 p=0.43\right.$; Figures $\left.2 \mathrm{G}, \mathbf{J}\right]$. In addition, we asked how many trials it took each mouse after goal reversal to regain a mean path length that was equal or shorter than on the last day of acquisition. Although there were variations 


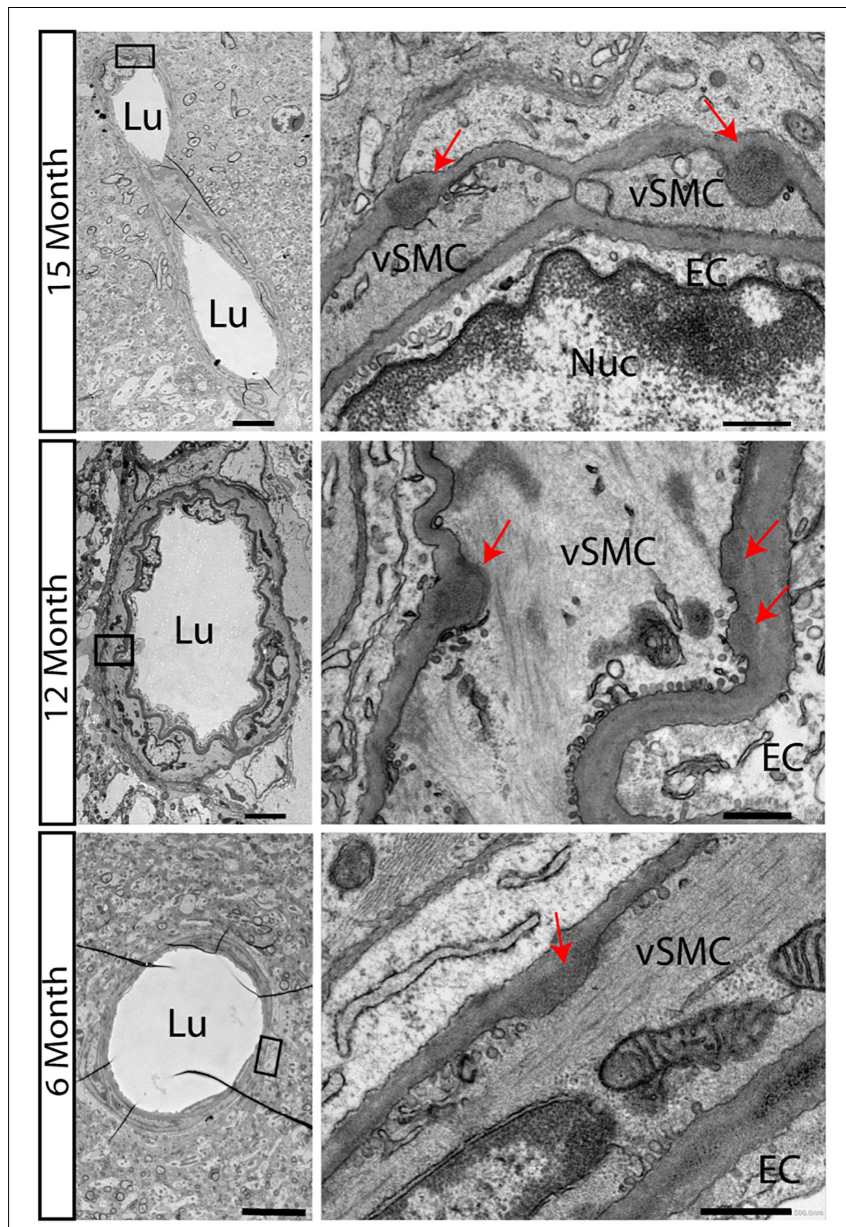

FIGURE 1 | Accumulations of GOMs in hippocampus of $\mathrm{TgN} 3^{R 169 C}$ mice. Electron microscopic analysis of the hippocampus in $\mathrm{TgN}^{R 169 C}$ mice showed accumulation of electron dense granular osmiophilic material at 15 and 12 months of age and less dense accumulation already at 6 months of age, as highlighted by the red arrow. Scale bar for left column $5 \mu \mathrm{m}$, right column $0.5 \mu \mathrm{m}$. EC, endothelial cells; Lu, Lumen; Nuc, Nucleus; vSMC, vascular smooth muscle cells.

between the different lines, no statistically significant difference could be detected [ANOVA $F_{(2,40)}=2.45, p=0.09$; Figure 2K]. The low $p$-value of 0.09 nevertheless indicates that further studies with increased power might reveal an effect of the mutation on the N3-dependent impairment.

In conclusion, the old platform position could be easily remembered, but CADASIL $\mathrm{TgN} 3^{R 169 C}$ mice showed deficits in up-dating the old context. A detailed analysis of the search strategies revealed that the mice used different strategies to locate the hidden platform. These strategies are indicative of the underlying cognitive processes and brain structures involved (Balschun et al., 2003; Garthe et al., 2009). Thus, we analyzed the search patterns (Figure 2E) of the mice while they were navigating to the hidden goal during task acquisition (days 14 ) and the reversal (days 5-7). Specifically, we compared the ratio of spatially directed effective search patterns to less directed patterns and thus less effective strategies shown by the TgN3 ${ }^{\mathrm{WT}}$ and $\operatorname{TgN} 3^{R 169 C}$ mice compared to WT mice (Figures $2 \mathbf{F}, \mathbf{H}$ ). Using a logistic regression, we statistically assessed changes in the chance (odds) for using either a more or less hippocampusdependent strategy. The estimated odds-ratio (OR) for transgenic mice overexpressing N3 compared to WT was $\mathrm{OR}=0.777$ $(p=0.004)$, whereas the CADASIL mutation resulted in estimated $\mathrm{OR}=0.936(p=0.063)$. Consequently, overexpression of N3 significantly impaired the use of spatial, more hippocampusdependent strategies, while the CADASIL mutation per se (in comparison to $\mathrm{N} 3$ overexpression) resulted in less severe deficits in the use of spatial strategies. In the reversal phase, perseverance could be seen predominantly in the N3 and CADASIL transgenic mice. We therefore applied the logistic regression model to the perseverance and found a significantly increased perseverance in CADASIL mutant mice ( $\mathrm{OR}=2.61, p=0.003$ ) in addition to the perseverance seen in $\mathrm{N} 3$ overexpressing mice $(\mathrm{OR}=2.36$, $p<0.001$; Figure 2I). These findings highlight that the R169C mutation resulted in deficits in up-dating of the allocentric map at this age, thereby resulting in an increased perseverance. These deficits are potentially due to a combined effect of vascular changes in the hippocampal niche (Ehret et al., 2015) and reduced adult neurogenesis. To confirm these neurogenic deficits in the modified mouse model, we carried out histological analysis of adult hippocampal neurogenesis.

\section{Deficits in Adult Neurogenesis in Aged N3 and CADASIL Transgenic Mice on the B6 Background}

We had previously found alterations in adult neurogenesis in these N3 and CADASIL transgenic mouse models on the FVB/N background (Ehret et al., 2015). In the new modified transgenic mouse model deficits due to N3 overexpression could be found at 12 months of age, which is in agreement with our previous observation. Also in line with the previous report, the CADASIL mutation did not additionally impact precursor proliferation and neuronal survival, as only differences to WT animals could be detected but not to the N3 overexpressing controls in this age group.

In detail, analysis of adult neurogenesis by BrdU revealed a reduction in cell survival in $\operatorname{TgN} 3^{R 169 C}\left[\operatorname{ANOVA} F_{(2,44)}=5.54\right.$, $p=0.007$, with $\operatorname{TgN} 3^{R 169 C}<\mathrm{WT} p=0.006$; Figure 3B]. Further phenotyping of $\mathrm{BrdU}^{+}$cells showed a decreased proportion of neuronal differentiation $\left[\mathrm{NeuN}^{+}\right.$; ANOVA $F_{(2,43)}=20.62$, $p<0.001$ with $\mathrm{TgN} 3^{W T}<\mathrm{WT} p<0.001$ and $\mathrm{TgN} 3^{R 169 C}<\mathrm{WT}$ $p<0.001]$ and an increase in astrocytic differentiation $\left[F_{(2,43)}=12.01, p<0.0001\right.$ with $\operatorname{TgN} 3^{W T}>$ WT $p=0.013$ and $\mathrm{TgN}^{R 169 C}>\mathrm{WT} p<0.0001$; Figure 3C,E,F]. While net gliogenesis was not altered [ANOVA $F_{(2,44)}=0.39 p=0.67$ ], net neurogenesis was reduced in both N3 and CADASIL transgenic animals [ANOVA $F_{(2,44)}=12.19, p<0.0001$ with TgN $3{ }^{\mathrm{WT}}<\mathrm{WT}$ $p=0.002$ and $\mathrm{TgN} 3^{R 169 C}>\mathrm{WT} p=0.0002$; Figure 3D]. The morphology of $\mathrm{BrdU}^{+}$new neurons and new astrocytes in both N3 and CADASIL transgenic mice appeared normal as shown in Figures 3E,F. For further confirmation of these results, we counted the number of calretinin ${ }^{+}$cells in the SGZ of the DG as an independent marker for immature neurons in 


\section{A Experimental Protocol}

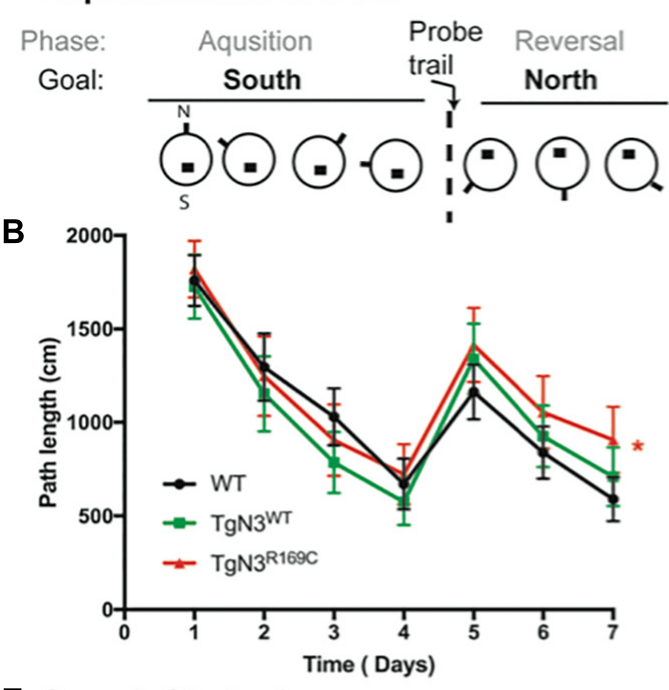

E Search Strategies
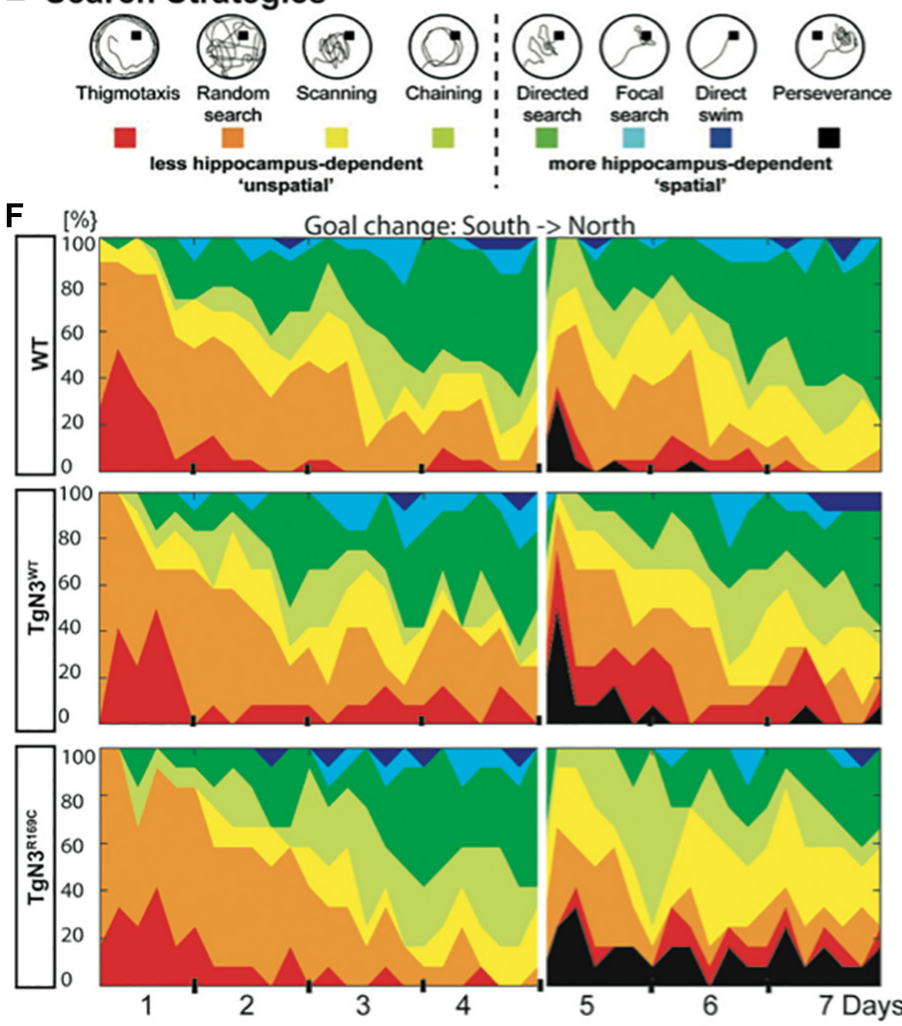

H Search Strategies I Perseverance spatial vs unspatial
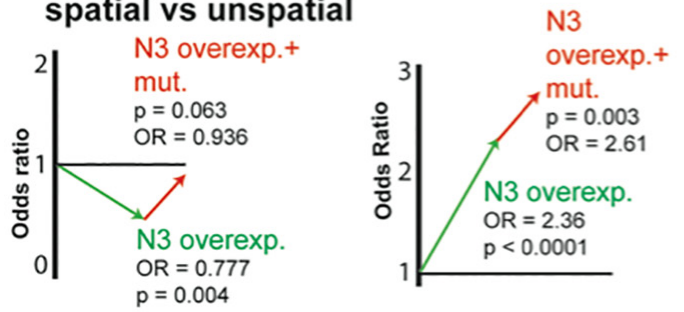
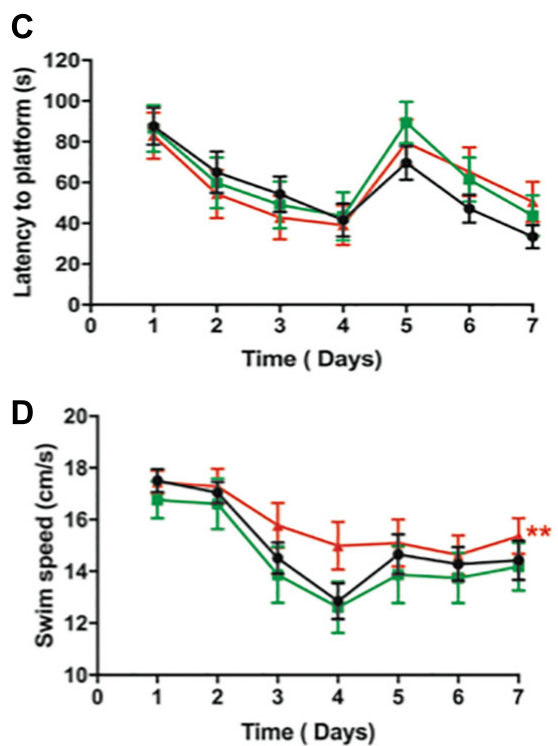

Time ( Days)

\section{G Probe Trial}
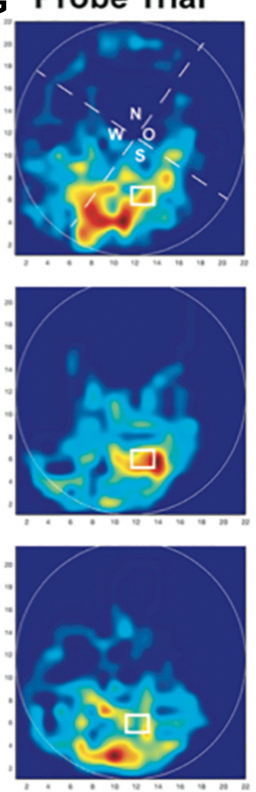

FIGURE 2 | Continued 
FIGURE 2 | Impaired spatial learning in the Morris water maze task in Notch3 and CADASIL transgenic mice at 12 months of age. (A) The experimental protocol of the Morris water maze task adjusted for aged animals and thus containing 4 days of acquisition and 3 days of reversal. (B) Analysis of path length showed an impaired performance after platform relocation in CADASIL mice ( ${ }^{\star}$ represents $\left.p<0.05\right)$. (C) Analysis of latency shows similar trends but no significant effect since the swim speed is significant higher in TgN3 ${ }^{R 169 C}$. (D) Swim speed of CADASIL mice differed significantly compared to N3 transgenic controls ( ${ }^{\star \star} p<0.01$ ). (E) Examples for classification of search strategies used to define "unspatial" vs. "spatial" more hippocampus-dependent patterns. (F) Contribution of the respective search strategies to group performance, color code as indicated in (E). (G) Heat maps from the respective animal groups of the probe trial performance (only the first $30 \mathrm{~s}$ ). (H) Graphic illustration of the induced change in the odds to choose a more hippocampus-dependent strategy as uncovered by logistic regression analysis based on previous classification shown in (E). (I) Graphic illustration of the induced change in the odds for perseverance based strategy in the reversal phase of the Morris water maze task. (J) Analysis of former goal crossings as an indicator of target accuracy in the probe trials. No impairment in previous goal location can be seen in transgenic mice. (K) Number of trials an individual animal needed to regain the average path length of day 4.

the adult dentate gyrus (Kempermann et al., 2004; Mattiesen et al., 2009; Knoth et al., 2010). A reduction in the number of calretinin ${ }^{+}$cells was found [ANOVA $F_{(2,46)}=8.61 p=0.0007$ with $\mathrm{TgN} 3^{\mathrm{WT}}<\mathrm{WT} p=0.018$ and $\mathrm{TgN} 3^{R 169 C}<\mathrm{WT} p=0.001$; Figure $3 \mathbf{A}]$, and thus these results were in line with the BrdU data (representative images shown in Supplementary Figure 1).

In conclusion, N3 overexpression reduced survival and differentiation potential of precursor cells in adulthood with no significant additional effect of the CADASIL mutation. A correlation analysis was carried out (Supplementary Figure 2) to gain further information about a link between the mutation, the neurogenesis effect and the behavioral findings. In the $\mathrm{TgN} 3^{\mathrm{WT}}$ mice, a strong cluster of neurogenesis and gliogenesis parameters was found, which was weaker in WT and TgN $3^{R 169 C}$ animals. Further, a positive correlation between water maze performance and adult neurogenesis was detected as described previously (Kempermann and Gage, 2002). Adult neurogenesis correlated well to the performance on the last day of acquisition (day 4) when the mice were most efficient in finding the hidden platform. CADASIL transgenic animals on the other hand did not show such strong positive correlations between adult neurogenesis and hippocampus-dependent learning, although they overexpressed $\mathrm{N} 3$ to the same extent. Thus, $\mathrm{TgN} 3^{R 169 \mathrm{C}}$ showed clusters of positive correlations for water maze performance throughout all trials, which indicated that these mice behaved more predictable and therefore, presumably, less flexible. This is corroborated by the finding that a correlation to neurogenesis could be detected only on the first day of reversal, when relearning is just starting and mice randomly search for the new platform.

In conclusion, the correlation analysis indicated that N3 is a regulator of adult neurogenesis and gliogenesis and might influence hippocampus-dependent learning in our animal model. The CADASIL mutation partly reverted the behavioral effects of N3 but not on adult neurogenesis.

\section{Deficits in Spatial Learning and Reduced Neurogenesis in N3 Transgenic Mice at 6 Months of Age}

As first GOM accumulations were already present at 6 months of age (Figure 1), we also asked whether the described phenotypes were already present at this much younger age, possibly offering insight into the developmental process that leads to the described changes.
At 6 months of age, CADASIL and N3 transgenic mice on the B6 background learned the Morris water maze task quickly and did not show any deficits during acquisition. The analysis of latencies throughout the experiment, with 3 days acquisition and 2 days reversal (Figure 4A), showed no significant differences of $\mathrm{N} 3$ transgenic mice to find the hidden platform (Chi-Square $=5.2, p=0.09$; Figure 4C). Swim speed, however, differed significantly (Chi-Square $=8.4$, $p=0.008$; Figure 4D), as $\mathrm{TgN} 3^{\mathrm{WT}}$ mice were significantly slower compared to WT $(p=0.006)$. Consequently, the analysis of path length as a less confounded measure was used, but did not reveal a significant difference (Chi-Square $=0.77$ $p=0.76$; Figure 4B). Although CADASIL mice showed slight deficits in remembering the previous platform location as the heat maps of the probe trial illustrate (Figure 4G). Nevertheless, analysis of probe trial performance revealed no significant differences in target accuracy, which was assessed by the number of former goal crossings (Chi-Square $=0.625$, $p=0.73$; Figure 4J) and the time spent in the target zone [ANOVA $F_{(2,53)}=2.073, p=0.135$; Figure 4I]. A closer look into the learning strategies (Figure 4E) revealed that N3 overexpression led to a reduction of spatial, hippocampusdependent strategies (Figure 4F). Analysis of the spatial versus non-spatial strategies by logistic regression revealed an $\mathrm{OR}=0.62(p=0.007)$ for $\mathrm{N} 3$ overexpressing mice (Figure $4 \mathbf{H}$ ). The CADASIL mutation on the other side resulted in an OR $=1.436(p=0.009)$, indicating that at this age CADASIL mice used more spatial cues as N3 transgenic controls.

As hippocampus-dependent learning seemed to be partially impaired in N3 transgenic mice at 6 months of age, we carried out a detailed analysis of precursor proliferation and differentiation in the adult hippocampus. As expected from our study on the FVB/N background (Ehret et al., 2015), histological analysis revealed that adult neurogenesis, in particular precursor proliferation and differentiation, was impaired at 6 months in N3 and CADASIL transgenic mice to the same extent. Hence, also the number of young neurons, as analyzed by calretinin immune labeling (Supplementary Figure 1), was significantly reduced in $\mathrm{N} 3$ and CADASIL transgenic mice [ANOVA $F_{(2,35)}=85, p<0.0001$ with $\mathrm{TgN} 3^{\mathrm{WT}}<\mathrm{WT}$, $p<0.0001$ and $\operatorname{TgN} 3^{R 169 C}<\mathrm{WT} p<0.0001$; Figure 5A]. Similar results were obtained by the analysis of $\mathrm{BrdU}^{+}$cells 28 days post injection [ANOVA $F_{(2,35)}=19.56, p<0.0001$ with $\mathrm{TgN} 3^{W T}<\mathrm{WT}, p<0.0001$ and TgN3 ${ }^{R 169 C}<\mathrm{WT}, p<0.0001$ Figure 5B; representative images Supplementary Figure 1]. 


\section{At 12 month}

\section{A Young Neurons}

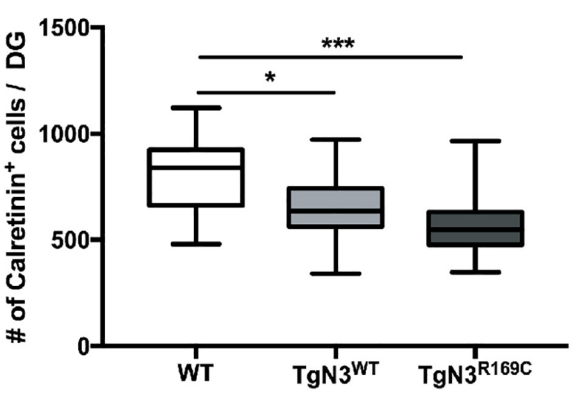

\section{Phenotype of Newborn Cells \\ $\square \mathrm{BrdU}^{+} / \square \mathrm{BrdU}^{+} \mathrm{Q} \square$ only $\mathrm{BrdU}^{+}$}
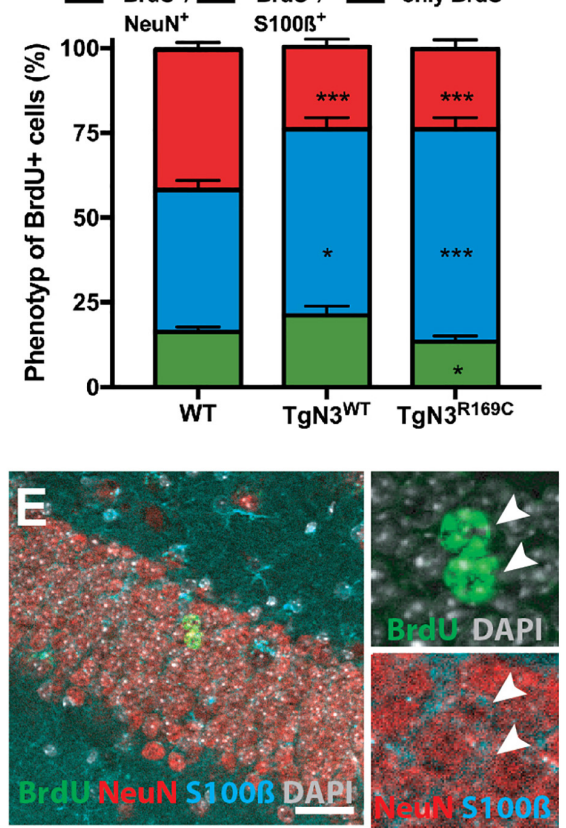

\section{B Newborn Cells}

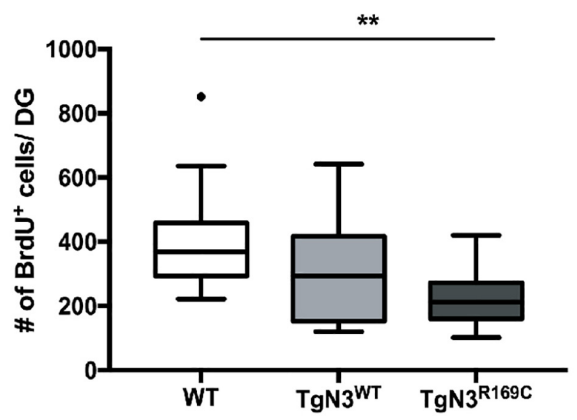

D Newborn Neurons
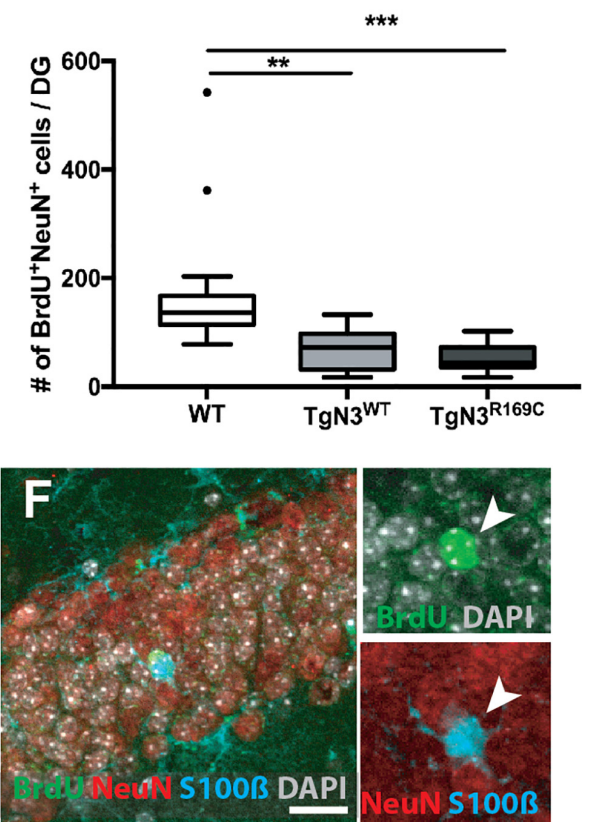

FIGURE 3 | Reduced adult neurogenesis in Notch3 and CADASIL transgenic mice at 12 months of age. (A) The number of calretinin ${ }^{+}$cells, as a marker for young neurons, is reduced in the SGZ of the DG of Notch3 and CADASIL transgenic mice. (B) Analysis of adult neurogenesis by the number of BrdU+ cells 28 days post injection showed a reduction in CADASIL transgenic animals. (C) Phenotyping of BrdU+ cells located in the SGZ of the DG with neuronal marker (NeuN) and astrocyte marker $(\mathrm{S} 100 \beta)$ showed decreased neuronal differentiation and an increased astrocytic differentiation of Notch3 and CADASIL transgenic mice compared to WT, Data = Mean \pm SEM. (D) Net neurogenesis, as calculated by number of $\mathrm{BrdU}^{+} / \mathrm{NeuN}^{+}$cells, is reduced in Notch3 and CADASIL transgenic mice. (E,F) Representative image from TgN3 ${ }^{R 169 C}$ mice of two $\mathrm{BrdU}^{+} / \mathrm{NeuN}^{+}$neurons $(\mathbf{E})$ and a BrdU $+/ \mathrm{S} 100 \beta^{+}$astrocyte (F), scale bar $30 \mu \mathrm{m} . \mathrm{N}=19$ for WT and 13 for $\mathrm{TgN3}^{\mathrm{WT}}$ and TGN3 ${ }^{\mathrm{C} 169 \mathrm{C}}$ for all graphs. Asterisks indicate statistical significance $\left({ }^{\star} p<0.05,{ }^{{ }^{\star}} p<0.01,{ }^{{ }^{\star \star \star}} p<0.005\right)$; DG, dentate gyrus; SGZ, subgranular zone.

Phenotyping of $\mathrm{BrdU}^{+}$cells revealed a reduction in neuronal differentiation (as measured by $\%$ of $\mathrm{BrdU}^{+} / \mathrm{NeuN}^{+}$co-labeling) in CADASIL transgenic mice in comparison to WT mice [ANOVA $F_{(2,25)}=3.41, p=0.0049$ with $\mathrm{TgN} 3^{R 169 C}<\mathrm{WT}$, $p=0.047$; Figure 5C]. Further, an increase in astrocytic differentiation (measured by $\%$ of $\mathrm{BrdU}^{+} / \mathrm{S} 100 \beta^{+}$co-labeling) in CADASIL transgenic mice in comparison to WT mice [ANOVA $F_{(2,25)}=4.62, p=0.019 ; \operatorname{TgN} 3^{R 169 C}>\mathrm{WT} p=0.025$ ] was observed. As a result, net neurogenesis was reduced in $\mathrm{N} 3$ and CADASIL transgenic mice [ANOVA $F_{(2,13)}=10$, $p=0.002$ with TgN3 ${ }^{W T}<\mathrm{WT}, p=0.004$ and $\mathrm{TgN} 3^{R 169 C}<\mathrm{WT}$, $p=0.007$; Figure 5D]. Nevertheless, net gliogenesis was not altered [ANOVA $F_{(2,13)}=1.2, p=0.32$ ]. These results indicate that in $\mathrm{N} 3$ overexpressing mice, adult neurogenesis is already impaired at an early age, which is in line with the observed albeit mild deficits in hippocampus-dependent spatial search strategies in the Morris water maze task. The CADASIL mutation in contrast, did not lead to an additional impairment in precursor proliferation or differentiation in this transgenic mouse model on C57BL/6J background. 


\section{A Experimental Protocol \\ Phase: \\ Aqusition Probe Reversal \\ Goal :

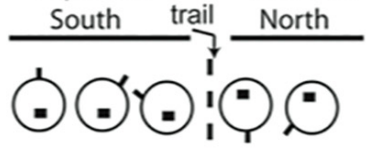

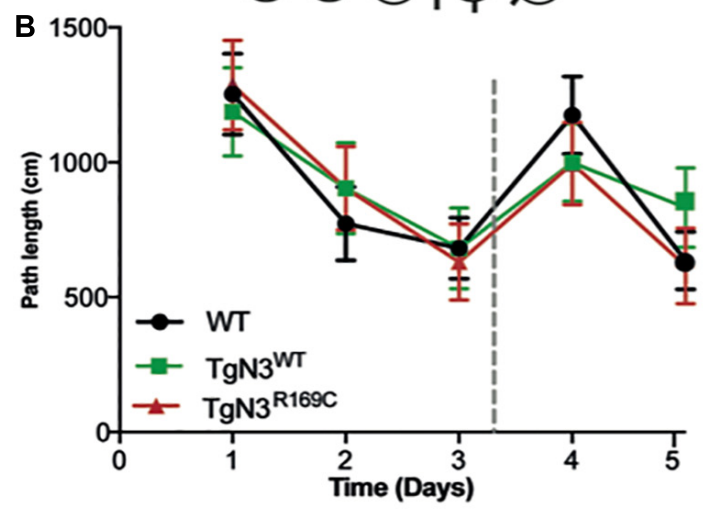

C

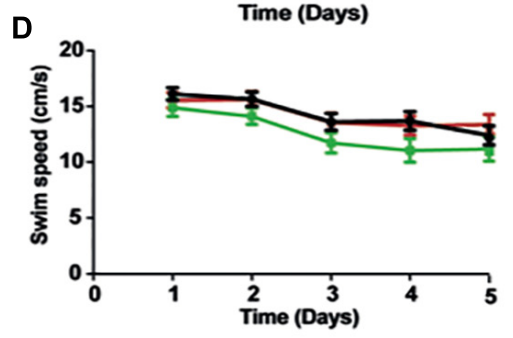

E

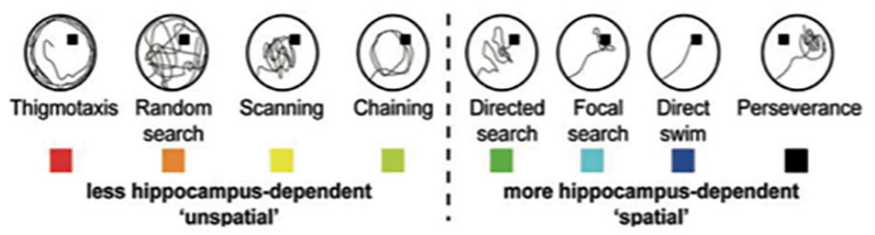

$\mathbf{F}$
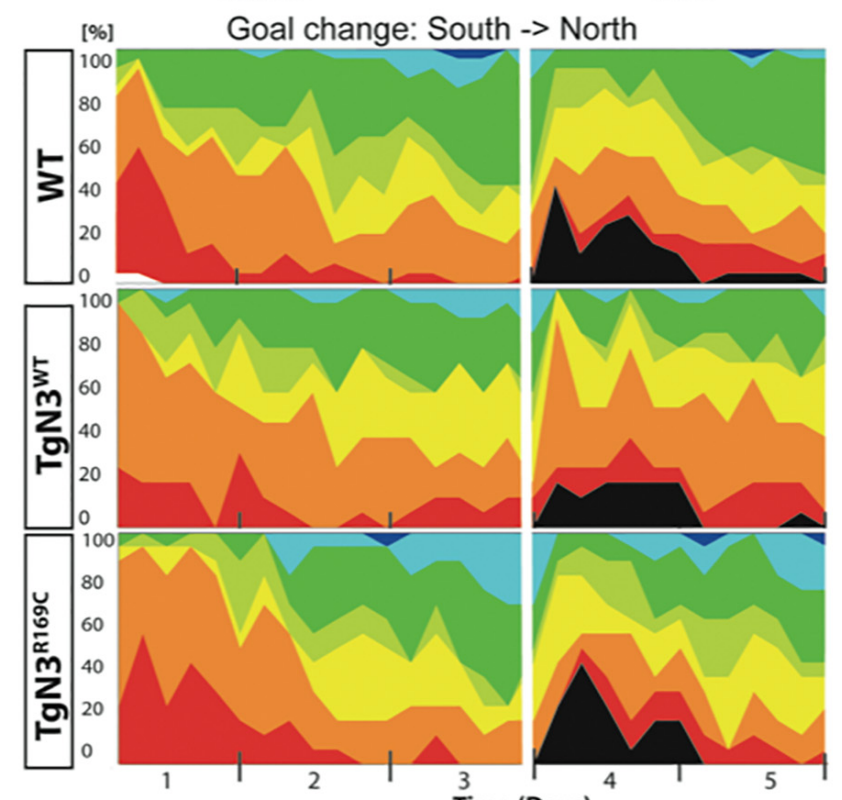

G Probe Trial
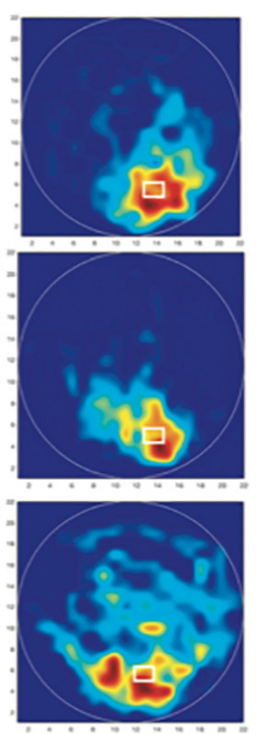

H

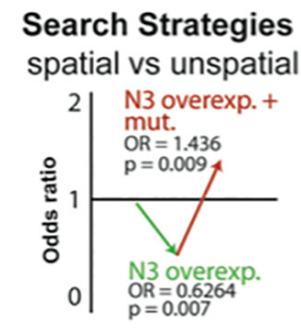

I Probe Trial

Time in Target zone

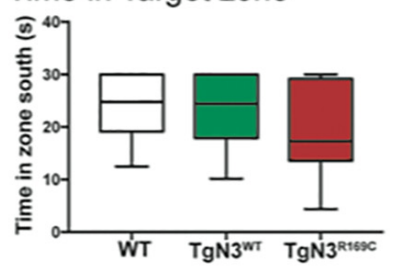

J Probe Trial

Target Accuracy

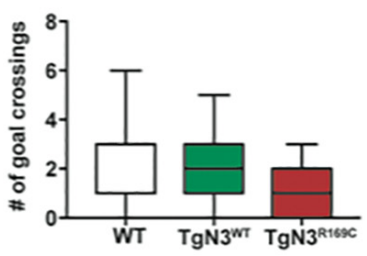


FIGURE 4 | Morris water maze task in Notch3 and CADASIL transgenic mice at 6 months of age. (A) The experimental protocol of the Morris water maze task containing 3 days of acquisition and 2 days of reversal. (B) Analysis of path length showed no deficits in performance. (C) Analysis of latency showed deficits, but since swim speed is reduced in TgN3 ${ }^{W T}$ path length is a more reliable measure. (D) Swim speed of TgN3 ${ }^{W T}$ mice is reduced compared to WT and TgN3 ${ }^{R 169 C}$. (E) Classification of search strategies. (F) Contribution of the respective search strategies to group performance, color code as indicated in (E). (G) Probe trial performance of the respective animal groups indicated by heat maps (only the first 30 s were plotted). Dark-red zones represent a 6-fold presence probability. (H) Graphic illustration of the induced change in the odds to choose a more hippocampus-dependent strategy, which is determined by logistic regression analysis based on classification shown in (E). The values indicated that Notch3 overexpression leads to the use of less spatial cues and that the CADASIL mutation per se results in the use of more spatial cues, which brought TGN3 ${ }^{R 169 C}$ mice back to WT levels. (I) Analysis of time spent in target zone during the first $30 \mathrm{~s}$ of probe trial as indicator of target accuracy. (J) Analysis of former goal crossings as a precise indicator of target accuracy in the probe trials. Although CADASIL transgenic mice showed less target accuracy of the previous goal location, no significant changes can be detected with the applied measures.

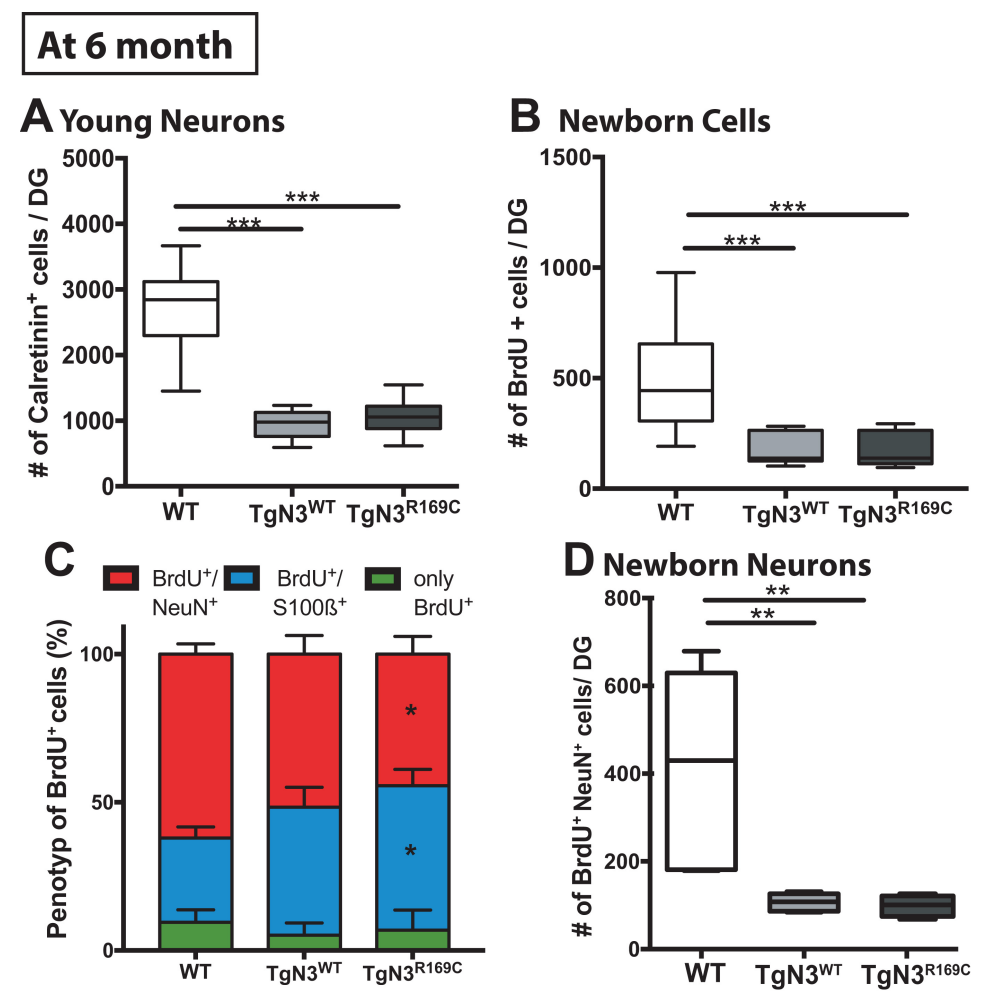

FIGURE 5 | Reduced adult neurogenesis in Notch3 and CADASIL transgenic mice at 6 months of age. (A) The number of calretinin ${ }^{+}$cells, as a marker for young neurons, is reduced in the SGZ of the DG of Notch3 and CADASIL transgenic mice. (B) Analysis of adult neurogenesis by the number of BrdU ${ }^{+}$cells 28 days post injection showed a reduction in Notch 3 and CADASIL transgenic animals. (C) Phenotyping of BrdU ${ }^{+}$cells with neuronal marker (NeuN) and astrocyte marker $(\mathrm{S} 100 \beta)$ showed decreased neuronal differentiation and an increased astrocytic differentiation in CADASIL transgenic mice compared to WT, Data $=$ Mean \pm SEM. (D) Net neurogenesis, as calculated by number of BrdU $+/ \mathrm{NeuN}^{+}$cells, is reduced in Notch3 and CADASIL transgenic mice. N = 15 WT and 12 for TgN3WT and $\mathrm{TgN}^{R 169 C}$ in all graphs. Asterisks indicate statistical significance $\left({ }^{\star} p<0.05,{ }^{\star \star} p<0.01,{ }^{\star \star \star} p<0.005\right)$, DG, dentate gyrus; SGZ, subgranular zone.

\section{Attempt to Study Adult Neurogenesis in CADASIL Patient Samples}

Based on our current and previous observation (Ehret et al., 2015) of a potential direct regulatory influence of N3 on adult hippocampal neurogenesis and the loss-of-function deficits seen in CADASIL transgenic mice, we intended to analyze adult neurogenesis also in patient samples. We were aware of the fact that there are substantial challenges to assessing adult neurogenesis in human specimens (Kempermann et al., 2018; Moreno-Jimenez et al., 2019). Histological analysis on hippocampal samples collected from the CADASIL brain bank (Leiden, Netherlands) showed calretinin-positive cells in the dentate gyrus (Figure 6B) of both patient and control specimens, indicative of adult hippocampal neurogenesis (Brandt et al., 2003; Mattiesen et al., 2009; Knoth et al., 2010; Boldrini et al., 2018). Interneurons were distinguished from immature granular cells based on size and location (shown in Figures 6C,D). Additional neurogenic markers were tested but did not produce convincing results in these specimens (see Supplementary Table B). All samples were checked for confounding effects of age, sex and post-mortem interval, when the areal density of calretinin-positive cells was assessed (Supplementary Figure 3). Altough post-mortem delay did not negatively influence density, no statistical differences in density of calretinin-positive cells were found (Figure 6A). Given the rareness of this disease 

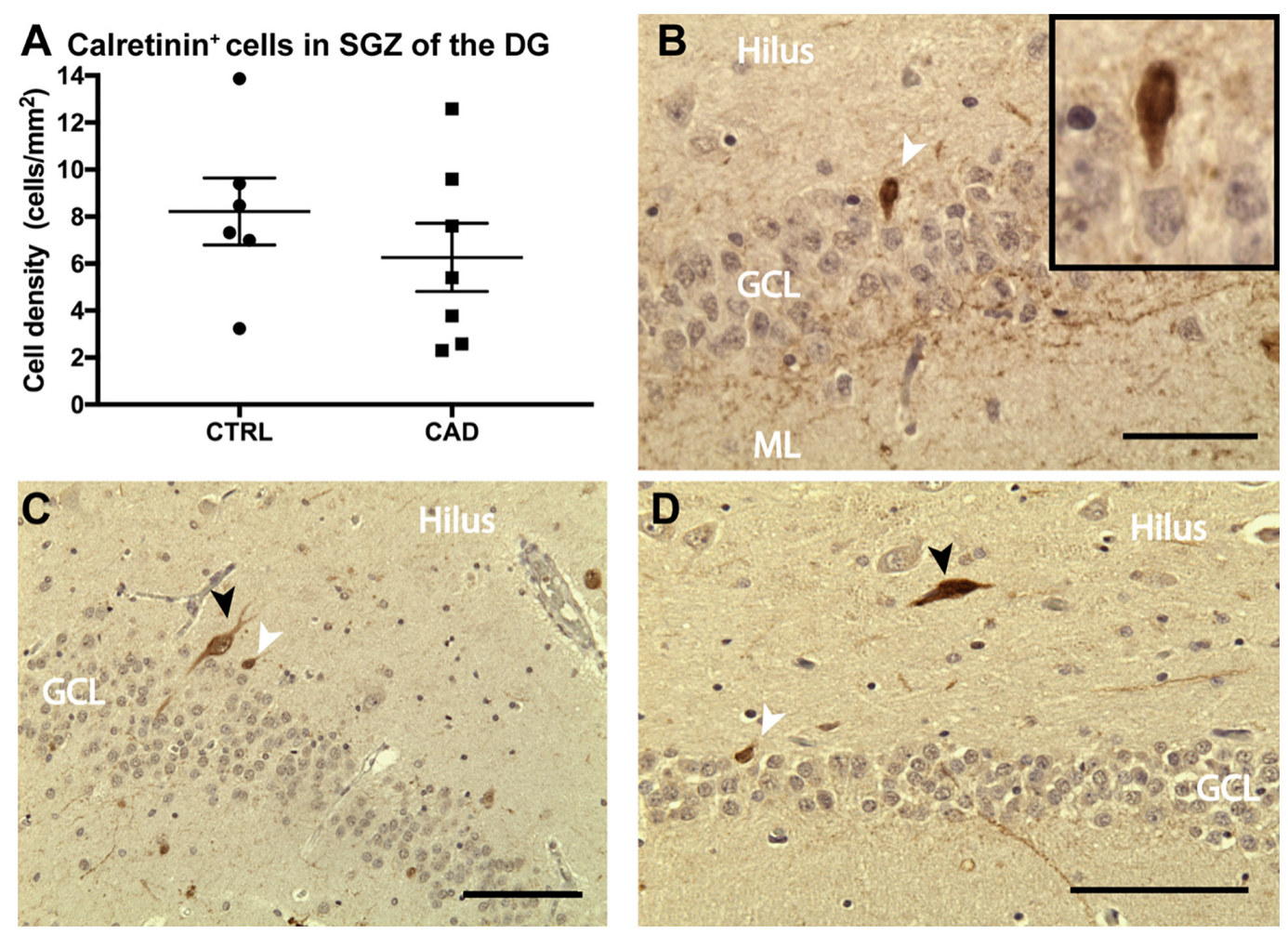

FIGURE 6 | Calretinin expression in the dentate gyrus of CADASIL post-mortem samples. (A) Number of calretinin ${ }^{+}$new born neurons per area of the granular cell layer (GCL) of control (CTRL) and CADASIL (CAD) patient samples. Cell density was averaged over 4-6 sections per patient. (B-D) Representative micrograph of calretinin $^{+}$new born neurons (white arrow) and larger Interneurons (black arrow), which are mainly found the hilus of human DG from CADASIL (B,D) and Control patients (C). Tissue was counter stained by haematoxylin. ML, molecular layer. Data = Mean \pm SEM, $N=6-7$, Scale bar $50 \mu \mathrm{m}$.

(and related tissue samples), it was unfortunate that no stereological quantification was possible and the results remain unconclusive with respect to a potential effect of CADASIL on adult neurogenesis.

\section{DISCUSSION}

The present study aimed at further elucidating the potential involvement of the hippocampus and failing adult neurogenesis in the manifestation of CADASIL. We had previously shown that $\mathrm{N} 3$ plays an essential role in adult neurogenesis, controlling aspects of precursor proliferation, activation and differentiation (Ehret et al., 2015). This is of particular relevance for CADASIL, since the functional consequences of the several established CADASIL mutations, including the $\mathrm{R} 169 \mathrm{C}$ mutation investigated here, have still no yet been comprehensively described. The current study identified deficits in hippocampus-dependent spatial memory in CADASIL transgenic mice. The observed behavioral phenotype was mild and could not be explained by N3-dependent effects on adult neurogenesis, because the mutation did not affect the neurogenesis phenotype beyond the $\mathrm{N} 3$ effect.
At the same time we confirmed that a regulatory influence of N3 appears to be critical for a variety of neural stem and precursor cells (Kawai et al., 2017; Than-Trong et al., 2018). The differential activation and differentiation of stem and precursor cells might lead to a deficient use of spatial search strategies. Previous studies had shown that, if adult neurogenesis was abolished, as for example in Cyclin D2 knockout mice (Garthe et al., 2014), after irradiation (Snyder et al., 2005), or after treatment with a cytostatic agent (Garthe et al., 2009; Goodman et al., 2010), flexible relearning was impaired. In the present study we could show that with increasing age especially this reversal learning is impaired in R169C CADASIL transgenic mice. So far, only one other CADASIL study had looked into spatial learning, but re-learning had not been assessed (Liu et al., 2015). The limitation of the model lies on the fact that it relies on N3 overexpression. Some of the effects of the mutation (on the ratio of spatial vs. unspatial strategies but not on perseverance) unveiled a loss of function that reverted or counteracted the pure N3 effects.

The used animal model is based on a strong (4-fold overexpression) of N3 with an endogenous-like expression pattern due to a PAC-based transgenesis approach (Joutel et al., 2010). Both transgenic lines express rat N3 at similar levels in addition to the endogenous mouse N3 protein (Supplementary 
Figure 4). Since the overexpression per se has such a strong effect on stem and progenitor cells, the additional functional deficits observed through the mutation are rather small and thus hard to distinguish from the overexpression phenotype. Nevertheless only models with at least 2-4 fold overexpression have been able to represent the spectrum of disorders observed in CADASIL patients like the occurrence of GOMs, white matter brain lesions and vascular deficits (Joutel et al., 2010). In comparison to the previous evaluation of this model on the FVB/N background, fewer deficits could be detected in neurogenesis at the early stage of 6 months. Our studies thus add to the body of literature that describes how strongly the effect of a mutation depends on the genetic background.

Generally, in dementias, such as in Alzheimer's disease, re-learning and recall are prominently affected (Karantzoulis and Galvin, 2011; Tort-Merino et al., 2017). In CADASIL patients this has not yet been specifically analyzed and only deficits in working memory, short-term memory, recall of verbal memory as well as executive and organizational functions have been studied (Taillia et al., 1998; Amberla et al., 2004; Epelbaum et al., 2011). Impaired adult neurogenesis does not affect spatial learning per se; it is relevant for specific aspects like up-dating of a previously formed cognitive map (Zhang et al., 2008; Garthe et al., 2014) and behavioral pattern separation (Clelland et al., 2009). There is theoretical and experimental evidence to support that adult neurogenesis levels do not correlate with probe trial performance but with water maze acquisition (Kempermann and Gage, 2002). Our data further support this view since adult neurogenesis $\left(\mathrm{BrdU}^{+} / \mathrm{NeuN}^{+}\right)$correlated to water maze performance (Day 2 and 4 ) for WT and TgN3 3 WT mice (Supplementary Figure 2). However, no correlation between adult neurogenesis and the acquisition phase of Morris water maze was found in CADASIL transgenic mice; only a correlation to the reversal phase and perseverance was observed. This indicates that aged CADASIL transgenic mice partially lack the flexibility of relearning a new spatial position. The use of spatial search strategies was impaired in N3 transgenic mice and almost back to WT levels in CADASIL transgenic mice, which partially supports a partial loss of function phenotype as found previously for this CADASIL mutation (Ehret et al., 2015). N3 overexpression on the side leads to predominantly less hippocampusdependent strategies (Figure $\mathbf{2 H}$ ) and perseverance after platform reversal.

Thus, these results confirm the critical involvement of N3 in precursor cell proliferation, activation and differentiation (Ehret et al., 2015; Kawai et al., 2017; ThanTrong et al., 2018), which might have direct functional consequences for the flexible integration of new information into previously established contexts (Garthe et al., 2009; Garthe and Kempermann, 2013). On the other hand, these results show that the impairment seen in CADASIL transgenic mice due to the mutation itself seems to be an additional component diminishing only certain aspects of plasticity and thus influencing the up-dating of the existing allocentric map, but do not per se lead to a loss of function phenotype. GOM accumulations and other subtle aspects of the pathology might additionally impair hippocampal function. Taken together, a complex relationship of vascular and neurogenic origin might influence hippocampusdependent function in CADASIL, specifically with respect to the R169C mutation.

Since we know the limitation of the available murine CADASIL models, we also intended to analyze adult neurogenesis in human tissue sections. We had the opportunity to undertake the present study with rare CADASIL tissue samples from Leiden University and tested several histological markers (DCX, PCNA, Prox1, Sox2) and protocols (for details see Supplementary Table B) based on previously described markers (Knoth et al., 2010). Of these, only Calretinin immune reactivity could be consistently established. Further the structural diversity in the human hippocampal samples made stereological investigations impossible so that no strong quantitative data could be obtained. This limitation was further aggravated by the fact that cell counts needed to be normalized to area of the granular cell layer (Moreno-Jimenez et al., 2019), a common approach to compensate for the comprehensive stereotaxic analysis that would otherwise be desirable but relies on homogenous tissue samples or very high N. Nevertheless, to grossly evaluate potential regionspecific differences, we subdivided the hippocampus into head, body and tail structures (Duvernoy and Vannson, 1988). Of these, the head region seemed to show some prominent changes in cell density (Supplementary Figure 5). Regional specific differences have not been evaluated by MRI in CADASIL patients so far, but the hippocampal head is sensitively affected in Alzheimer's disease and mild cognitive impairment (Wang et al., 2003; Feng et al., 2018), schizophrenia (O’Driscoll et al., 2001), epilepsy (Bernasconi et al., 2003), and traumatic brain injury (Ariza et al., 2006). Regional differences, if confirmed, would therefore be in line with other studies. Other than that, our study unfortunately remained inconclusive with respect to adult neurogenesis in patient samples.

We present the data nevertheless, because omitting the description of the unsuccessful attempt would create a publication bias in that positive findings are generally more likely to be published than negative or ambiguous results. Data on adult hippocampal neurogenesis in humans are scarce and problematic to obtain, partly because of the limited availability of specimen to be studied. This applies particularly to disease cases, such as CADASIL. With calretinin we could only assess one, obviously robust, marker, which by itself could not settle the case. But it is important that attempts are published and the difficulties and challenges are made public, because of the high expectations on studies on adult neurogenesis in disease contexts to include human data.

Independent of this question, our study provides evidence for an involvement of N3 in structural and functional plasticity of the hippocampus by controlling aspects of cell proliferation, activation and differentiation, which has functional consequences for spatial memory. In addition, the CADASIL mutation seems to 
partially impair N3 function affecting spatial memory function in the Morris water maze task.

\section{DATA AVAILABILITY STATEMENT}

The raw data supporting the conclusions of this article will be made available by the authors, without undue reservation.

\section{ETHICS STATEMENT}

The animal study was reviewed and approved by the Landesdirektion Sachsen, Dresden, Germany. For the provided human data, all participants gave informed consent that their samples could be used for research and publication.

\section{AUTHOR CONTRIBUTIONS}

FE and GK planned the study and wrote the manuscript. FE, RMT, M-TN, BH, and DL performed the experiments. FE analyzed the data. GK supervised the entire project and provided financial support. All authors contributed to the article and approved the submitted version.

\section{REFERENCES}

Amberla, K., Waljas, M., Tuominen, S., Almkvist, O., Poyhonen, M., Tuisku, S., et al. (2004). Insidious cognitive decline in CADASIL. Stroke J. Cerebral Circ. 35, 1598-1602. doi: 10.1161/01.STR.0000129787.92085.0a

Ariza, M., Serra-Grabulosa, J. M., Junque, C., Ramirez, B., Mataro, M., Poca, A., et al. (2006). Hippocampal head atrophy after traumatic brain injury. Neuropsychologia 44, 1956-1961. doi: 10.1016/j.neuropsychologia.2005.11.007

Balschun, D., Wolfer, D. P., Gass, P., Mantamadiotis, T., Welzl, H., Schutz, G., et al. (2003). Does cAMP response element-binding protein have a pivotal role in hippocampal synaptic plasticity and hippocampus-dependent memory? J. Neurosci. 23, 6304-6314.

Bernasconi, N., Bernasconi, A., Caramanos, Z., Antel, S. B., Andermann, F., and Arnold, D. L. (2003). Mesial temporal damage in temporal lobe epilepsy: a volumetric MRI study of the hippocampus, amygdala and parahippocampal region. Brain $126(\mathrm{Pt} 2), 462-469$.

Boldrini, M., Fulmore, C. A., Tartt, A. N., Simeon, L. R., Pavlova, I., Poposka, V., et al. (2018). Human hippocampal neurogenesis persists throughout aging. Cell Stem Cell 58:e585. doi: 10.1016/j.stem.2018.03.015

Brandt, M. D., Jessberger, S., Steiner, B., Kronenberg, G., Reuter, K., Bick-Sander, A., et al. (2003). Transient calretinin expression defines early postmitotic step of neuronal differentiation in adult hippocampal neurogenesis of mice. Mol. Cell Neurosci. 24, 603-613.

Buffon, F., Porcher, R., Hernandez, K., Kurtz, A., Pointeau, S., Vahedi, K., et al. (2006). Cognitive profile in CADASIL. J. Neurol. Neurosurg. Psychiatry 77, 175-180. doi: 10.1136/jnnp.2005.068726

Burghardt, N. S., Park, E. H., Hen, R., and Fenton, A. A. (2012). Adult-born hippocampal neurons promote cognitive flexibility in mice. Hippocampus 22, 1795-1808. doi: 10.1002/hipo.22013

Chabriat, H., Joutel, A., Dichgans, M., Tournier-Lasserve, E., and Bousser, M. G. (2009). Cadasil. Lancet Neurol. 8, 643-653. doi: 10.1016/S1474-4422(09) 70127-9

Clelland, C. D., Choi, M., Romberg, C., Clemenson, G. D. Jr., Fragniere, A., Tyers, P., et al. (2009). A functional role for adult hippocampal neurogenesis in spatial pattern separation. Science 325, 210-213. doi: 10.1126/science.1173215

Duvernoy, H. M., and Vannson, J. L. (1988). The Human Hippocampus : An Atlas of Applied Anatomy. München: J.F. Bergmann-Verlag München.

\section{FUNDING}

This work was financed by basic institutional funds (DZNE). FE was supported by Peter and Traudl Engelhorn-Stiftung.

\section{ACKNOWLEDGMENTS}

The authors like to thank Saskia A. J. Lesnik Oberstein (Leiden University) for collaboration on the human tissue samples from the Leiden brain bank, Ingrid Hegeman for human sample preparation, Sandra Günter and Anne Karasinsky for mouse handling, Peggy Oloth for technical assistance, Christina Steinhauer for molecular work, Benedikt Asay for help with EM preparations, and Thomas Kurth for EM preparations and imaging.

\section{SUPPLEMENTARY MATERIAL}

The Supplementary Material for this article can be found online at: https://www.frontiersin.org/articles/10.3389/fnagi. 2021.617733/full\#supplementary-material

Ehm, O., Goritz, C., Covic, M., Schaffner, I., Schwarz, T. J., Karaca, E., et al. (2010). RBPJkappa-dependent signaling is essential for long-term maintenance of neural stem cells in the adult hippocampus. J. Neurosci. 30, 13794-13807. doi: 10.1523/JNEUROSCI.1567-10.2010

Ehret, F., Vogler, S., Pojar, S., Elliott, D. A., Bradke, F., Steiner, B., et al. (2015). Mouse model of CADASIL reveals novel insights into Notch3 function in adult hippocampal neurogenesis. Neurobiol. Dis. 75, 131-141. doi: 10.1016/j.nbd. 2014.12.018

Epelbaum, S., Benisty, S., Reyes, S., O’Sullivan, M., Jouvent, E., During, M., et al. (2011). Verbal memory impairment in subcortical ischemic vascular disease: a descriptive analysis in CADASIL. Neurobiol. Aging 32, 2172-2182. doi: 10.1016/ j.neurobiolaging.2009.12.018

Farley, S. J., McKay, B. M., Disterhoft, J. F., and Weiss, C. (2011). Reevaluating hippocampus-dependent learning in FVB/N mice. Behav. Neurosci. 125, 871878. doi: 10.1037/a0026033

Feng, F., Wang, P., Zhao, K., Zhou, B., Yao, H., Meng, Q., et al. (2018). Radiomic features of hippocampal subregions in Alzheimer's disease and amnestic mild cognitive impairment. Front. Aging Neurosci. 10:290. doi: 10.3389/fnagi.2018. 00290

Garthe, A., Behr, J., and Kempermann, G. (2009). Adult-generated hippocampal neurons allow the flexible use of spatially precise learning strategies. PLoS One 4:e5464. doi: 10.1371/journal.pone.0005464

Garthe, A., Huang, Z., Kaczmarek, L., Filipkowski, R. K., and Kempermann, G. (2014). Not all water mazes are created equal: Cyclin D2 knockout mice with constitutively suppressed adult hippocampal neurogenesis do show specific spatial learning deficits. Genes Brain Behav. 13, 357-364. doi: 10.1111/gbb. 12130

Garthe, A., and Kempermann, G. (2013). An old test for new neurons: refining the Morris water maze to study the functional relevance of adult hippocampal neurogenesis. Front. Neurosci. 7:63. doi: 10.3389/fnins.2013.00063

Garthe, A., Roeder, I., and Kempermann, G. (2016). Mice in an enriched environment learn more flexibly because of adult hippocampal neurogenesis. Hippocampus 26, 261-271. doi: 10.1002/hipo.22520

Goodman, T., Trouche, S., Massou, I., Verret, L., Zerwas, M., Roullet, P., et al. (2010). Young hippocampal neurons are critical for recent and remote spatial memory in adult mice. Neuroscience 171, 769-778. doi: 10.1016/j.neuroscience. 2010.09.047 
Imayoshi, I., Sakamoto, M., Yamaguchi, M., Mori, K., and Kageyama, R. (2010). Essential roles of Notch signaling in maintenance of neural stem cells in developing and adult brains. J. Neurosci. 30, 3489-3498. doi: 10.1523/ JNEUROSCI.4987-09.2010

Joutel, A., Monet-Lepretre, M., Gosele, C., Baron-Menguy, C., Hammes, A., Schmidt, S., et al. (2010). Cerebrovascular dysfunction and microcirculation rarefaction precede white matter lesions in a mouse genetic model of cerebral ischemic small vessel disease. J. Clin Investig. 120, 433-445. doi: 10.1172/ JCI39733

Karantzoulis, S., and Galvin, J. E. (2011). Distinguishing Alzheimer's disease from other major forms of dementia. Expert Rev. Neurother. 11, 1579-1591. doi: 10.1586/ern.11.155

Kawai, H., Kawaguchi, D., Kuebrich, B. D., Kitamoto, T., Yamaguchi, M., Gotoh, Y., et al. (2017). Area-specific regulation of quiescent neural stem cells by notch3 in the adult mouse subependymal zone. J. Neurosci. 37, 11867-11880. doi: 10.1523/JNEUROSCI.0001-17.2017

Kempermann, G. (2012). New neurons for 'survival of the fittest'. Nat. Rev. Neurosci. 13, 727-736. doi: 10.1038/nrn3319

Kempermann, G., Gage, F. H., Aigner, L., Song, H., Curtis, M. A., Thuret, S., et al. (2018). Human adult neurogenesis: evidence and remaining questions. Cell Stem Cell 23, 25-30. doi: 10.1016/j.stem.2018.04.004

Kempermann, G., and Gage, F. H. (2002). Genetic determinants of adult hippocampal neurogenesis correlate with acquisition, but not probe trial performance, in the water maze task. Eur. J. Neurosci. 16, 129-136.

Kempermann, G., Gast, D., Kronenberg, G., Yamaguchi, M., and Gage, F. H. (2003). Early determination and long-term persistence of adult-generated new neurons in the hippocampus of mice. Development 130, 391-399.

Kempermann, G., Jessberger, S., Steiner, B., and Kronenberg, G. (2004). Milestones of neuronal development in the adult hippocampus. Trends Neurosci. 27, 447-452. doi: 10.1016/j.tins.2004.05.013

Knoth, R., Singec, I., Ditter, M., Pantazis, G., Capetian, P., Meyer, R. P., et al. (2010). Murine features of neurogenesis in the human hippocampus across the lifespan from 0 to 100 years. PLoS One 5:e8809. doi: 10.1371/journal.pone. 0008809

Liu, X. Y., Gonzalez-Toledo, M. E., Fagan, A., Duan, W. M., Liu, Y., Zhang, S., et al. (2015). Stem cell factor and granulocyte colony-stimulating factor exhibit therapeutic effects in a mouse model of CADASIL. Neurobiol. Dis. 73, 189-203. doi: 10.1016/j.nbd.2014.09.006

Lugert, S., Basak, O., Knuckles, P., Haussler, U., Fabel, K., Gotz, M., et al. (2010). Quiescent and active hippocampal neural stem cells with distinct morphologies respond selectively to physiological and pathological stimuli and aging. Cell Stem Cell 6, 445-456. doi: 10.1016/j.stem.2010.03.017

Mattiesen, W. R., Tauber, S. C., Gerber, J., Bunkowski, S., Bruck, W., and Nau, R. (2009). Increased neurogenesis after hypoxic-ischemic encephalopathy in humans is age related. Acta Neuropathol. 117, 525-534. doi: 10.1007/s00401009-0509-0

Moreno-Jimenez, E. P., Flor-Garcia, M., Terreros-Roncal, J., Rabano, A., Cafini, F., Pallas-Bazarra, N., et al. (2019). Adult hippocampal neurogenesis is abundant in neurologically healthy subjects and drops sharply in patients with Alzheimer's disease. Nat. Med. 25, 554-560. doi: 10.1038/s41591-0190375-9

Morris, R. (2007). The Hippocampus Book. Oxford: Oxford University Press.
O’Driscoll, G. A., Florencio, P. S., Gagnon, D., Wolff, A. V., Benkelfat, C., Mikula, L., et al. (2001). Amygdala-hippocampal volume and verbal memory in firstdegree relatives of schizophrenic patients. Psychiatry Res. 107, 75-85.

O'Keefe, J., and Dostrovsky, J. (1971). The hippocampus as a spatial map. Preliminary evidence from unit activity in the freely-moving rat. Brain Res. 34, $171-175$.

O’Sullivan, M., Ngo, E., Viswanathan, A., Jouvent, E., Gschwendtner, A., Saemann, P. G., et al. (2009). Hippocampal volume is an independent predictor of cognitive performance in CADASIL. Neurobiol. Aging 30, 890-897. doi: 10. 1016/j.neurobiolaging.2007.09.002

Pugh, P. L., Ahmed, S. F., Smith, M. I., Upton, N., and Hunter, A. J. (2004). A behavioural characterisation of the FVB/N mouse strain. Behav. Brain Res. 155, 283-289. doi: 10.1016/j.bbr.2004.04.021

Snyder, J. S., Hong, N. S., McDonald, R. J., and Wojtowicz, J. M. (2005). A role for adult neurogenesis in spatial long-term memory. Neuroscience 130, 843-852. doi: 10.1016/j.neuroscience.2004.10.009

Spalding, K. L., Bergmann, O., Alkass, K., Bernard, S., Salehpour, M., Huttner, H. B., et al. (2013). Dynamics of hippocampal neurogenesis in adult humans. Cell 153, 1219-1227. doi: 10.1016/j.cell.2013.05.002

Taillia, H., Chabriat, H., Kurtz, A., Verin, M., Levy, C., Vahedi, K., et al. (1998). Cognitive alterations in non-demented CADASIL patients. Cerebrovasc. Dis. 8 , 97-101.

Than-Trong, E., Ortica-Gatti, S., Mella, S., Nepal, C., Alunni, A., and BallyCuif, L. (2018). Neural stem cell quiescence and stemness are molecularly distinct outputs of the Notch3 signalling cascade in the vertebrate adult brain. Development 145, dev161034. doi: 10.1242/dev.161034

Tort-Merino, A., Valech, N., Penaloza, C., Gronholm-Nyman, P., Leon, M., Olives, J., et al. (2017). Early detection of learning difficulties when confronted with novel information in preclinical Alzheimer's disease stage 1. J. Alzheimers Dis. 58, 855-870. doi: 10.3233/JAD-161173

Voikar, V., Koks, S., Vasar, E., and Rauvala, H. (2001). Strain and gender differences in the behavior of mouse lines commonly used in transgenic studies. Physiol. Behav. 72, 271-281.

Wang, L., Swank, J. S., Glick, I. E., Gado, M. H., Miller, M. I., Morris, J. C., et al. (2003). Changes in hippocampal volume and shape across time distinguish dementia of the Alzheimer type from healthy aging. Neuroimage 20, 667-682. doi: 10.1016/S1053-8119(03)00361-6

Zhang, C. L., Zou, Y., He, W., Gage, F. H., and Evans, R. M. (2008). A role for adult TLX-positive neural stem cells in learning and behaviour. Nature 451, 1004-1007. doi: 10.1038/nature06562

Conflict of Interest: The authors declare that the research was conducted in the absence of any commercial or financial relationships that could be construed as a potential conflict of interest.

Copyright (c) 2021 Ehret, Moreno Traspas, Neumuth, Hamann, Lasse and Kempermann. This is an open-access article distributed under the terms of the Creative Commons Attribution License (CC BY). The use, distribution or reproduction in other forums is permitted, provided the original author(s) and the copyright owner(s) are credited and that the original publication in this journal is cited, in accordance with accepted academic practice. No use, distribution or reproduction is permitted which does not comply with these terms. 